\title{
Green synthesis of engineered CdS nanoparticles with reduced cytotoxicity for enhanced bio-imaging application
}

N Susha ${ }^{1}$, Prajit Janardhanan ${ }^{2}$, Rajendra Pilankatta ${ }^{2}$ and Swapna S Nair ${ }^{*}$.

${ }^{1}$ Department of Physics, Central University of Kerala, Kasaragod, INDIA.

${ }^{2}$ Department of Biochemistry and Molecular Biology, Central University of Kerala, Kasaragod, INDIA.

Supporting Information

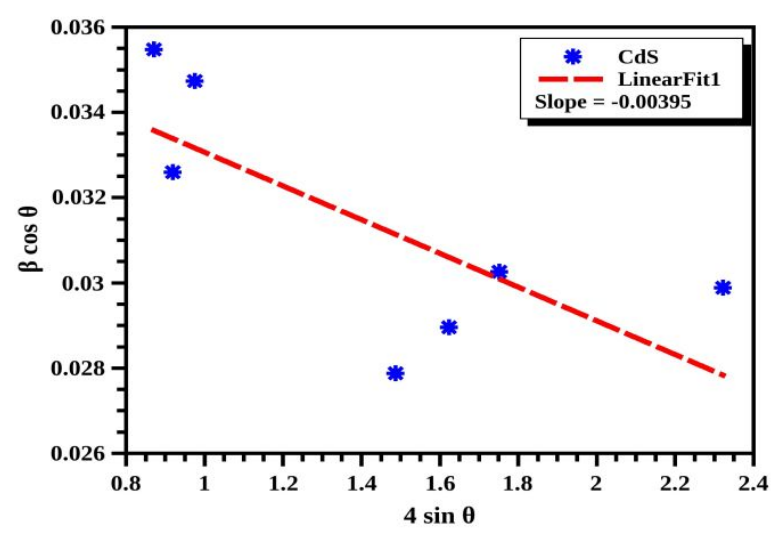

Figure S1: W-H plot of CdS nanoparticle.
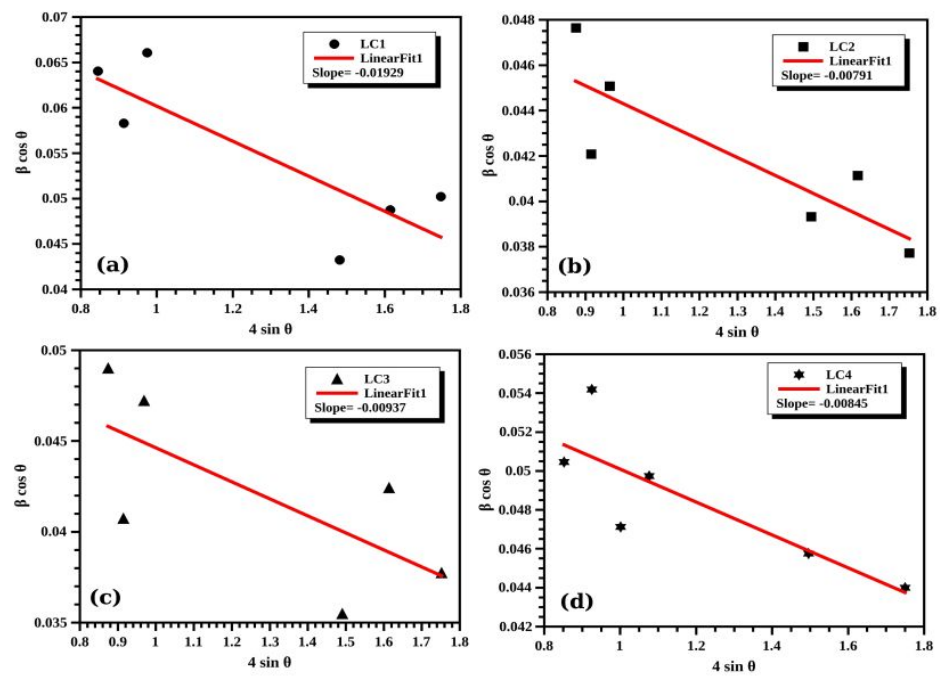

Figure S2: W-H plot of CdS-C. Odorata hybrid structures (a) LC1, (b) LC2, (c) LC3 and (d) LC4 

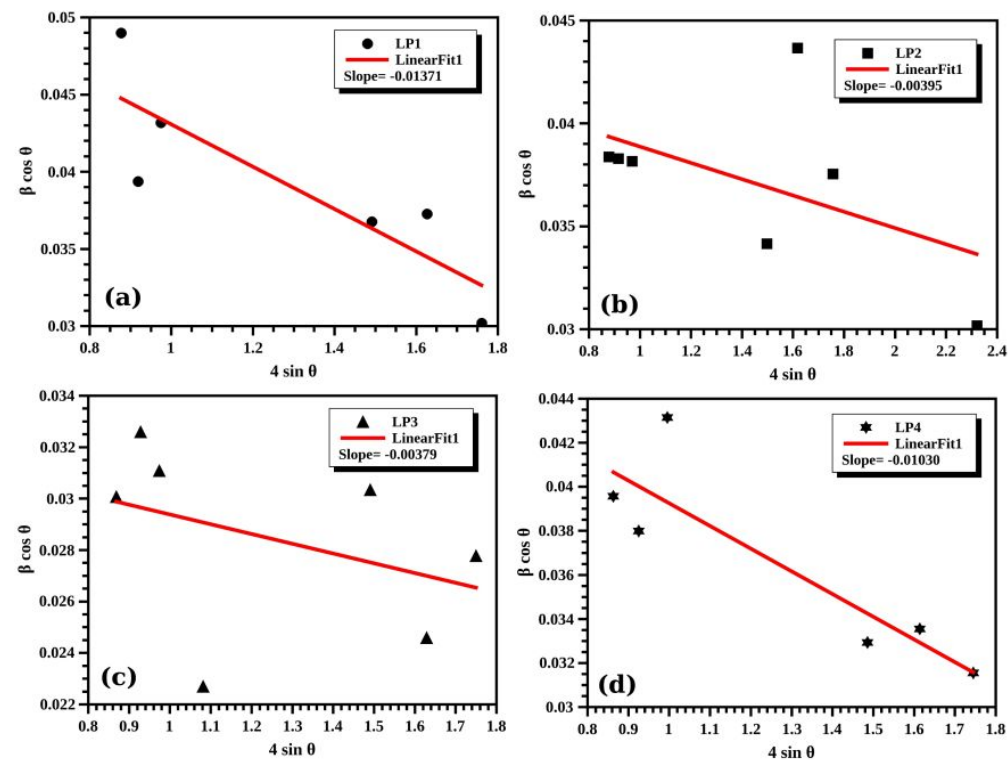

Figure S3: W-H plot of CdS-P. Amboinicus hybrid structures, (a) LP1, (b) LP2, (c) LP3 and (d) LP4
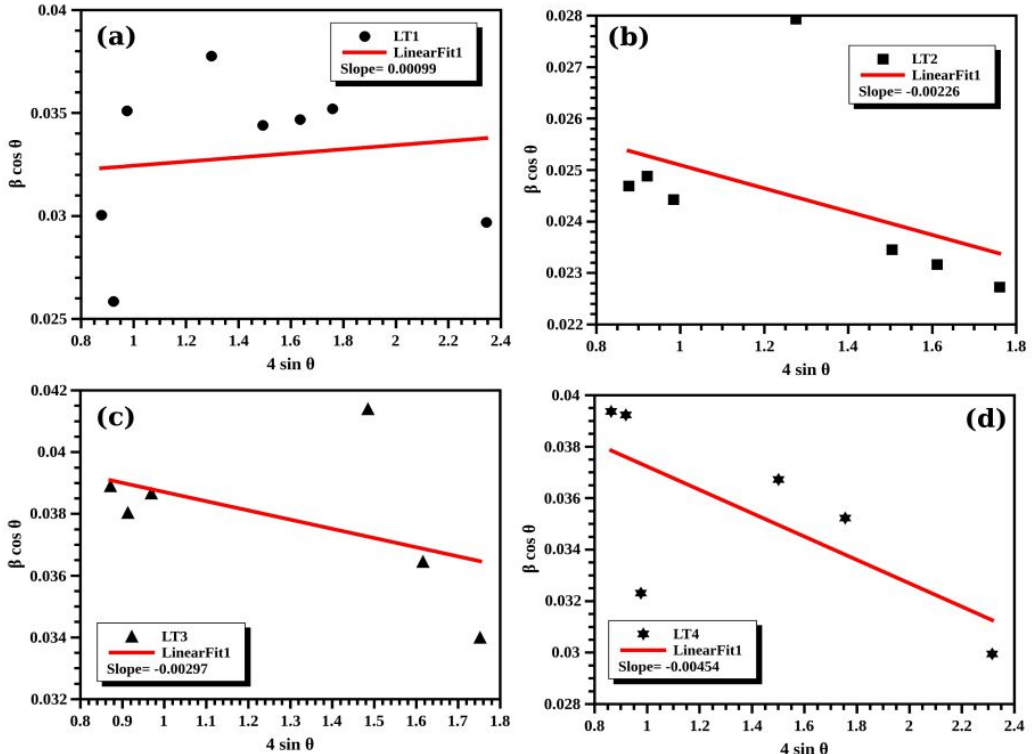

Figure S4: W-H plot of CdS-O. Tenuiflorum hybrid structures, (a) LT1, (b) LT2, (c) LT3 and (d) LT4. 
Table S1: Sample details with \% of leaf extract solution(C. Odorata (C), P. amboinicus (P) and $O$. tenuiflorum $(\mathrm{T})$ ), calculated lattice parameters and the crystallite size from XRD and W-H analysis

\begin{tabular}{|c|c|c|c|c|c|c|}
\hline $\begin{array}{l}\text { Sample } \\
\text { Name }\end{array}$ & $\begin{array}{c}\text { Total } \\
\text { volume } \\
\text { of leaf } \\
\text { extract }(\%)\end{array}$ & $\begin{array}{l}\text { Crystallite } \\
\text { size ( } \\
\text { A) }\end{array}$ & Strain & $\begin{array}{l}\text { Size from } \\
\text { W-H } \\
\text { Analysis } \\
\text { ( } \\
\text { A) }\end{array}$ & $\begin{array}{l}\text { a) } \\
\text { A) }\end{array}$ & $\begin{array}{l}\mathrm{c}( \\
\mathrm{A})\end{array}$ \\
\hline $\begin{array}{l}\text { CdS } \\
\text { LC1 } \\
\text { LC2 } \\
\text { LC3 } \\
\text { LC4 }\end{array}$ & $\begin{array}{c}0 \\
6 \\
10 \\
20 \\
50\end{array}$ & $\begin{array}{l}45 \\
26 \\
33 \\
33 \\
29\end{array}$ & $\begin{array}{l}-0.00395 \\
-0.01929 \\
-0.00791 \\
-0.00937 \\
-0.00845\end{array}$ & $\begin{array}{l}37 \\
18 \\
27 \\
26 \\
24\end{array}$ & $\begin{array}{l}4.09 \\
4.14 \\
4.08 \\
4.08 \\
4.11\end{array}$ & $\begin{array}{l}6.70 \\
6.75 \\
6.73 \\
6.70 \\
6.65\end{array}$ \\
\hline $\begin{array}{l}\text { LP1 } \\
\text { LP2 } \\
\text { LP3 } \\
\text { LP4 }\end{array}$ & $\begin{array}{c}6 \\
10 \\
20 \\
50\end{array}$ & $\begin{array}{l}36 \\
38 \\
49 \\
38\end{array}$ & $\begin{array}{l}-0.01317 \\
-0.00395 \\
-0.00379 \\
-0.01030\end{array}$ & $\begin{array}{l}24 \\
32 \\
42 \\
28\end{array}$ & $\begin{array}{l}4.07 \\
4.07 \\
4.09 \\
4.11\end{array}$ & $\begin{array}{l}6.71 \\
6.73 \\
6.63 \\
6.65\end{array}$ \\
\hline $\begin{array}{l}\text { LT1 } \\
\text { LT2 } \\
\text { LT3 } \\
\text { LT4 }\end{array}$ & $\begin{array}{c}6 \\
10 \\
20 \\
50\end{array}$ & $\begin{array}{l}43 \\
57 \\
37 \\
39\end{array}$ & $\begin{array}{c}0.00099 \\
-0.00226 \\
-0.00297 \\
-0.00454\end{array}$ & $\begin{array}{l}45 \\
51 \\
34 \\
33\end{array}$ & $\begin{array}{l}4.07 \\
4.06 \\
4.11 \\
4.09\end{array}$ & $\begin{array}{l}6.67 \\
6.69 \\
6.76 \\
6.69\end{array}$ \\
\hline
\end{tabular}



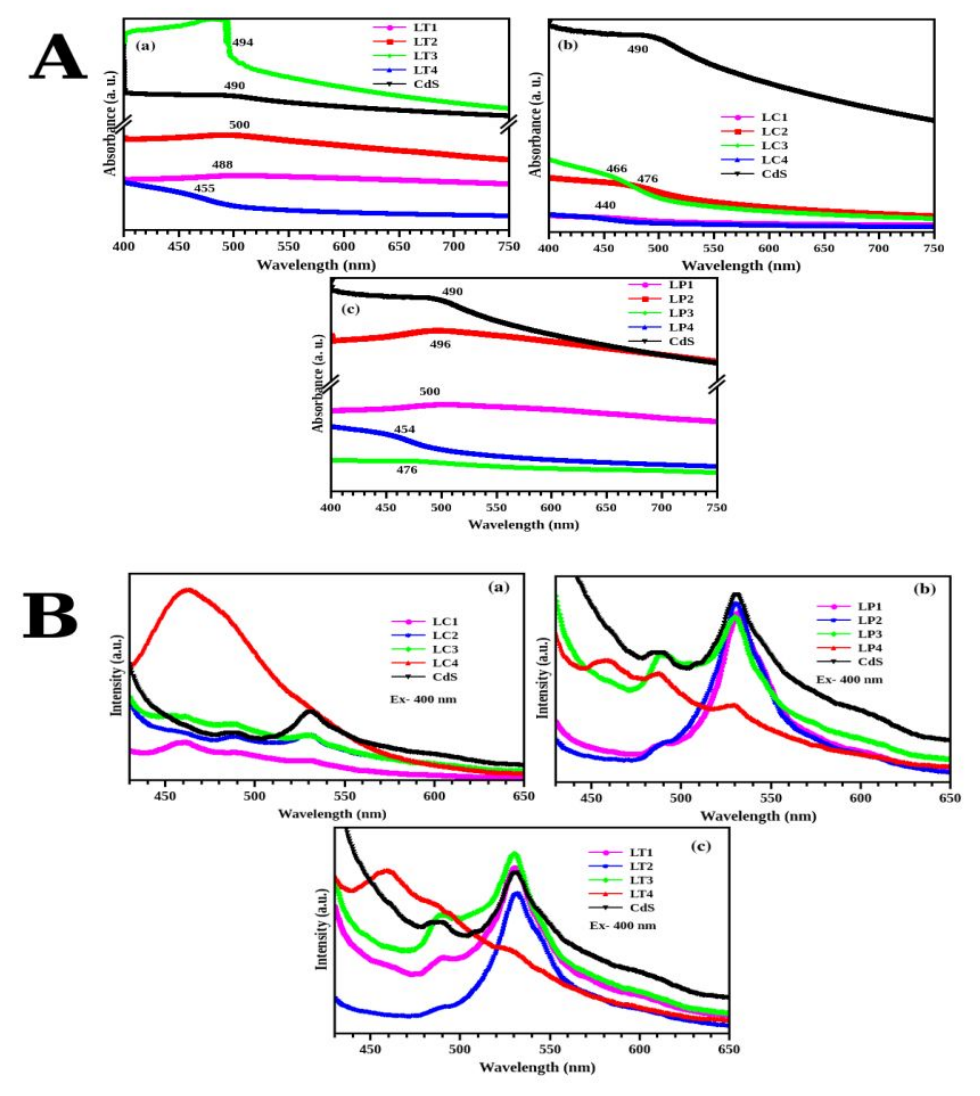

Figure S5: (A) Absorption spectra of the (a) CdS-C. odorata (b) CdS-P. amboinicus and (c) CdS-O. tenuiflorum hybrid structures in comparison with the CdS nanoparticles (B) Emission spectra of all the CdS-GS extract hybrid at an excitation of $400 \mathrm{~nm}$ (a) LC series (b) LP series and (c) LT series.

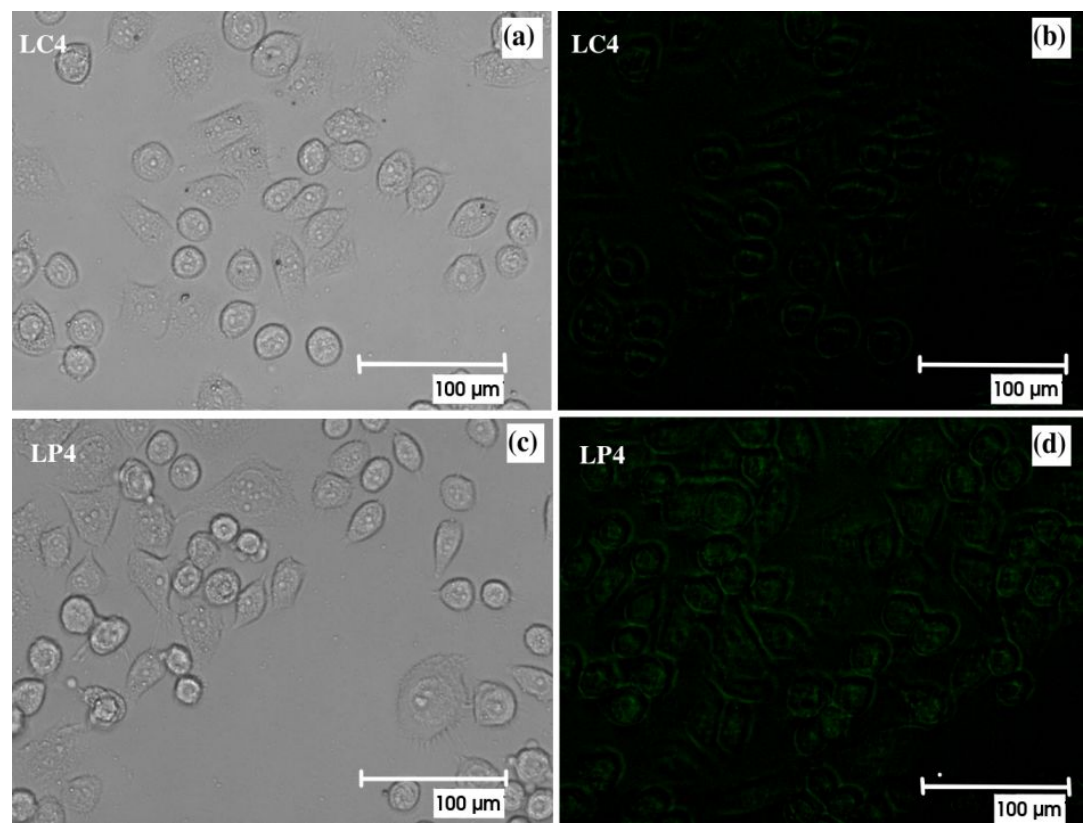

Figure S6: Bright field and fluorescent images of the cell with the presence of CdS- C.Odorata (a,b) and that of CdS-P. Amboinicus (c,d). 